\title{
Effect of interfacial oxidation occurring during the duplex process combining surface nanocrystallisation and co-rolling
}

\author{
L. Waltz ${ }^{\mathrm{a}}$, D. Retraint ${ }^{\mathrm{a},{ }^{*}}$, A. Roos ${ }^{\mathrm{a}}$, C. Garnier ${ }^{\mathrm{a}}$, P. Olier ${ }^{\mathrm{b}}$ \\ ${ }^{a}$ Charles Delaunay Institute, UMR CNRS 6279, LASMIS, University of Technology of Troyes, \\ 10000 Troyes, France \\ ${ }^{b}$ DEN/DNM/SRMA/LTMEX, Commissariat à l'Energie Atomique de Saclay, \\ 91191 Gif-sur-Yvette, France \\ *Corresponding author: \\ Tel.: +33 3257156 68, Fax: +33325715675 \\ E-mail address: delphine.retraint@utt.fr
}

\begin{abstract}
This paper presents an investigation of the interface quality of nanocristallised $316 \mathrm{~L}$ stainless steel multilayer structures. They were produced by a duplex process, combining the Surface Mechanical Attrition Treatment (SMAT) and the co-rolling process at two different annealing temperatures $\left(550^{\circ} \mathrm{C}\right.$ and $650^{\circ} \mathrm{C}$ ). Oxide layers were observed at the interfaces between the sheets and their morphology was characterised by optical microscopy. Their chemical composition was determined by Energy Dispersive $\mathrm{X}$-ray spectrometry. The microstructure near the interfaces was analysed by Transmission Electron Microscopy (TEM). In the laminate co-rolled at $550^{\circ} \mathrm{C}$, the presence of ultrafine grains was demonstrated. Additional tensile tests have shown an influence of the annealing temperature on the yield strength, as well as on the resistance of the interfaces of the co-rolled multilayer structures.
\end{abstract}

Keywords: SMAT; Co-rolling; Grain refinement; Mechanical characterisation; Oxidation; Nanostructured materials

\section{Introduction}

Nanocrystalline and ultrafine-grained metals and alloys with average grain size of less than $500 \mathrm{~nm}$ have generated widespread interest during the last decade because of their remarkable mechanical properties as compared to their coarse-grained counterparts [1]. However, despite high yield and ultimate strengths, a significant number of these studies has shown a very limited tensile ductility, often caused by residual porosities, impurities and flaws arising from the elaboration process. The most common nanocristallisation processes are inert gas consolidation, electrodeposition, powder compaction and severe plastic deformation techniques such as ECAE (Equal Channel Angular Extrusion), HPT (High Pressure Torsion), ARB (Accumulative Roll-Bonding) and SMAT (Surface Mechanical Attrition Treatment). The recently developed SMAT technique can induce grain refinement down to the nanometer scale in the top surface layer of metals and alloys such as iron, titanium, copper or stainless steel [1-4]. Unfortunately the affected depth remains limited $(\approx 250 \mu \mathrm{m}$ for $316 \mathrm{~L}$ stainless steel $)$, which leads to a rapid saturation of the yield strength of SMATed bulk materials [5]. To overcome this problem, a novel process has been developed to increase the volume fraction of nano-grains. This duplex process combines the SMAT with a subsequent co-rolling process in order to produce multilayered bulk structures with improved yield and ultimate tensile strengths, while conserving an acceptable elongation 
to failure. The duplex process is described in detail in $[5,6]$. However, during the heat treatment before co-rolling, the impurities deposited on the surface of SMATed samples cause bonding imperfections due to interfacial oxidation during the process.

In the present work, nanocristallised $316 \mathrm{~L}$ stainless steel multilayer structures were produced by the duplex process as described in [5, 6]. Two different rolling temperatures, $550^{\circ} \mathrm{C}$ and $650^{\circ} \mathrm{C}$, were imposed in order to quantify the effect of the heat treatment on the interface quality. The microstructures near the interface region of co-rolled samples were analysed by Optical Microscopy (OM). In addition, the oxide layers observed there were chemically characterised by Energy Dispersive X-ray spectrometry (EDX). Finally, uniaxial tensile tests were carried out at room temperature on the as-processed structures in order to study the influence of annealing on the macroscopic mechanical properties.

\section{Experimental procedures}

In this investigation a $316 \mathrm{~L}$ face centered cubic $(f c c)$ austenitic stainless steel with chemical composition as given in Table 1 was used. The initial microstructure of the as-received alloy after thermomechanical treatment and hyper-quenching, shown in Fig. 1, contains austenitic grains of 10 to $60 \mu \mathrm{m}$. A high density of mechanical and annealing twins can be observed within the grains. For the experimental tests, $120 \times 120 \times 1 \mathrm{~mm}^{3}$ plates were used. The surface nanocrystallisation of these sheets was carried out by SMAT in air at room temperature during 30 minutes, with $3 \mathrm{~mm}$ stainless steel shot at a vibration frequency of $20 \mathrm{kHz}$. A complete description of the SMAT process is given in [1].

The co-rolling of the assembly of three SMATed plates was carried out on a reversible rolling mill with a maximum capacity of $3500 \mathrm{kN}$. In both cases, the middle plate was SMATed on both sides, whereas the two outer plates were treated on their inner side only. Then, the plates were co-rolled in two passes with a total thickness reduction of $\approx 55 \%$, corresponding to a total equivalent strain of 0.88 . To identify the effect of annealing on the mechanical behaviour of the co-rolled samples and on their interface bonding, two different heat treatments were carried out: the samples were respectively corolled at $550^{\circ} \mathrm{C}$ (sample $\mathrm{T}_{\mathrm{SMAT}-550}$ ) and at $650^{\circ} \mathrm{C}$ (sample $\mathrm{T}_{\mathrm{SMAT}-650}$ ). These annealing temperatures were deliberately chosen near the dechromisation temperature of the stainless steel. For comparison, laminates of three plates have been co-rolled without SMAT at the interfaces, with the same reduction ratio and at the same annealing temperature (samples $\mathrm{T}_{\text {no SMAT-550 }}$ and $\mathrm{T}_{\text {no SMAT-650). }}$ ).

The microstructure of the co-rolled samples was characterised by transmission electron microscopy (TEM) on a $120 \mathrm{kV}$ LEO 912 OMEGA microscope. TEM plane-view samples were cut from the corolled samples near the interface region. A second TEM observation campaign was carried out on a PHILIPS CM200 FEG microscope with an accelerating voltage of $200 \mathrm{kV}$. For the latter, TEM samples were obtained from the co-rolled samples in the transverse plane defined by the rolling and normal directions (plane RD-ND). These samples allowed an adequate analysis of the microstructure near the interface, as well as the analysis of the chemical composition of the interface oxides by EDX.

Optical micrographs were obtained of the cross section (plane RD-ND) of samples $\mathrm{T}_{\mathrm{SMAT}-550}$ and $\mathrm{T}_{\mathrm{SMAT}-650}$ before and after electro-polishing at room temperature in a solution of $60 \%$ nitric acid and $40 \%$ water at a voltage of $1.5 \mathrm{~V}$. Moreover, the samples were polished to obtain a working surface near the plane defined by the rolling and transverse directions (RD-TD) as shown in Fig. 3 a).

In order to quantify the mechanical response of co-rolled structures, tensile tests were carried out at room temperature on a screw-driven Kammrath \& Weiss micro-tensile machine at a fixed strain rate of 
$10^{-4} \mathrm{~s}^{-1}$. Tensile samples with a total length of $36 \mathrm{~mm}$, a gauge length of $19 \mathrm{~mm}$ and an average crosssection of $1.4 \times 3.6 \mathrm{~mm}^{2}$ were machined by electrodischarge from the co-rolled samples.

\section{Results and discussion}

Preliminary OM observations were undertaken on co-rolled multilayer structures after mechanical polishing and without etching. The observations were principally carried out in the interface region as shown in the micrographs in Fig. 2 a) and b), which represent respectively the interface morphology and oxidation of the samples $T_{\text {SMAT-550 }}$ and $\mathrm{T}_{\text {SMAT-650. A significant difference between the oxide layers is }}$ observed. The laminate $\mathrm{T}_{\text {SMAT-550 }}$ contains discontinuous oxide clusters with heterogeneous thickness. Between the oxide islets, a good metal/metal bonding is observed. The interface of sample $\mathrm{T}_{\text {SMAT-650 }}$ is characterised by a continuous oxide layer with a uniform thickness of $1-2 \mu \mathrm{m}$. As shown by these micrographs, the higher annealing temperature for sample $\mathrm{T}_{\mathrm{SMAT}-650}$ has a significant effect on the oxidation in the interface region, and probably on the oxidation kinetics, which may explain the difference observed between the two laminates.

To provide a better understanding and analysis of the oxides, metallographic samples were obtained by mechanical polishing in an inclined plane near RD-TD (see Fig. 3 a)). The micrograph obtained for sample $\mathrm{T}_{\text {SMAT-550 }}$ thus prepared is given in Fig. $3 \mathrm{~b}$ ). The oxide cluster shown in this figure contains several colorations (red, blue, brown, gray and black) indicating the presence of oxides such as hematite $\left(\alpha-\mathrm{Fe}_{2} \mathrm{O}_{3}\right)$, magnetite $\left(\mathrm{Fe}_{2} \mathrm{O}_{4}\right)$ and different complex oxides resulting from the oxidation of various elements such as iron and chromium. In addition, a partial metal/oxide decohesion is noted, leading to the formation of cracks and micro-debonding in the interface region, which could be very harmful for the mechanical behaviour of co-rolled structures. This point will be discussed later.

Contradicting to some studies in the literature $[7,8]$, who claim that SMAT does not contaminate the treated materials, the SMAT used in the duplex process is strongly suspected to contribute to surface pollution. The three principal sources of pollution in the SMAT process that have been identified are the shot, the ultrasonic resonator and the treatment chamber. Polluting particles put in motion and/or transported by the shot are deposited on the surface of the samples during the treatment. Such surface pollution has been reported before by Cemin et al. [9] on a 316L stainless steel after surface mechanical attrition by ball milling. In the present study, the pollutants oxidise in air before and during the heat treatment. During co-rolling, complex oxides are then formed at the interfaces of the multilayer structures.

As shown in Fig. 4 a), a TEM sample was prepared from the cross section (plane RD-ND) of sample $\mathrm{T}_{\text {SMAT-550. }}$. This sample was used for analysing the chemical composition of the oxide layer at the interface. The thickness of the oxide layer in this region is about $200 \mathrm{~nm}$. The EDX measurements performed in the austenitic matrix show a chemical composition near to that given in Table I. The microanalyses of the oxidised interface region (Fig. 4 b)) show the presence of $\mathrm{Fe}, \mathrm{Cr}, \mathrm{Mn}$ and $\mathrm{O}$ elements in high proportion. This indicates that complex oxides are formed during the duplex process. Furthermore, the energy of the characteristic peak of the titanium emission spectrum is very atypical for the considered stainless steel alloy. The presence of titanium can be directly related to surface pollution by the TA6V titanium alloy ultrasonic resonator, and confirms the assumption that SMAT induces a surface pollution.

After the study of the interface region of the co-rolled multilayer structures without prior etching, a microstructural investigation was carried out after electro-polishing. Fig. 5 a-c) and a'-c') show the 
optical micrographs obtained for samples $\mathrm{T}_{\mathrm{SMAT}-550}$ and $\mathrm{T}_{\mathrm{SMAT}-650}$ respectively. It can be observed that the microstructure of these samples consists of deformed austenitic grains. Segregated bands developed during rolling, forming fibres in the middle of the three sheets composing the laminate, are also observed (Fig. 5 a) and a')). The shape of the grains through the cross-section of the laminates and the location of the fibres indicate that a large part of the plastic strain is accommodated in the middle of the sheets. These observations agree well with the local hardness measurements performed by Waltz et al. [6] on co-rolled laminates. There, the increase of the local hardness in the coarse grain matrix at the middle of the plates was entirely attributed to the work hardening during the rolling process. However, near the interface region, the $\gamma \rightarrow \alpha$ phase transformation activated by work hardening during SMAT contributes to the increase of the local hardness [6]. More details about the martensite formation occurring during SMAT can be found in [10-12].

As can be observed in Fig. 5, the oxide islets for sample $\mathrm{T}_{\text {SMAT-550 }}$ and the continuous oxide layer in the case of sample $\mathrm{T}_{\text {SMAT-650 }}$ become clearly visible after electro-polishing. Shear bands are present near the interface region around the oxide islets in sample $\mathrm{T}_{\text {SMAT-550, }}$ as can be seen in Fig. 5 b) and c). A similar shear band formation was reported by Kolahi et al. [13] and Quadir et al. [14], respectively in a roll-bonded aluminium strip and ferrite processed by warm rolling and ARB. This indicates that the oxide islets significantly disturb the material flow during the rolling. The material cannot flow uniformly and flows around the obstacle, which gives rise to plastic strain localisation in shear bands.

No similar bands were observed for sample $\mathrm{T}_{\mathrm{SMAT}-650}$, because of the different morphology of the oxide layer. The underlying processes explaining the differences are not yet clearly understood. The fragility of the oxide layer, the deterioration of its mechanical properties by raising the annealing temperature, coupled to dissolution and migration of the oxides in the metal matrix might be at the origin of these differences [15-19]. It is conceivable that the brittle oxides cannot accommodate the plastic strain during co-rolling at $550^{\circ} \mathrm{C}$. The result would be a multi-fissuration of the oxide layer during rolling. This hypothesis supports the one already expressed by Quadir et al. [14], who suggest that the bonding occurs by fracture of the oxide layers having a much lower ductility than the reference metal. At the origin of the fracture of the oxide layer is the formation of shear bands that break the oxide into single islets [14]. In this case, the underlying material, more ductile, could then diffuse into the cracks to form junctions by diffusion with the material extruded through the superficial oxide layer of the second sheet. This might explain the alternation of oxide islets and well-bonded areas between the sheets in sample $\mathrm{T}_{\mathrm{SMAT}-550}$ (see Fig. $5 \mathrm{~b}$-c)). For sample $\mathrm{T}_{\mathrm{SMAT}-650}$, the oxide layer remains continuous because of its increased ductility at the rolling temperature of $650^{\circ} \mathrm{C}$.

Another significant difference can be noted in the microstructures near the interface. In the case of sample $\mathrm{T}_{\mathrm{SMAT}-550}$, the microstructure near the interface is characterised by deformation bands and a high density of mechanical sub-micrometric twins within equiaxed grains, whereas sample $\mathrm{T}_{\text {SMAT-650 }}$ shows only micrometric grains elongated in the rolling direction. Twins observed in Fig. 5 c) are the result of the SMAT and are considered to be at the origin of a grain refinement in materials with low stacking fault energies (SFE), as discussed in $[1,3,5]$. These twins were eliminated by the thermomechanical treatment of laminate $\mathrm{T}_{\mathrm{SMAT}-650}$, and only a low density of annealing twins is visible.

Despite some difficulties caused by the thinning technique used in this work and by flatness defects of the co-rolled laminate, a TEM sample could be obtained from the ultrafine-grained layer. Fig. 6 displays a bright-field TEM micrograph showing the microstructure beneath the interface of the corolled laminate $\mathrm{T}_{\mathrm{SMAT}-550}$. By analysing this plane-view observation and its corresponding Selected Area Electron Diffraction (SAED) pattern, the microstructure in the interface region is characterised by a high density of dislocations, ultrafine equiaxed grains with nearly random crystallographic orientations, and 
sub-structures. Taking into account several electron micrographs, the mean grain size can be evaluated between 90 and $250 \mathrm{~nm}$. This indicates that the effect of SMAT is not annihilated after annealing at $550^{\circ} \mathrm{C}$, although the contribution of the deformation bands in the microstructural refinement remains currently unclear. TEM micrographs obtained near the interface of sample $\mathrm{T}_{\mathrm{SMAT}-650}$ (not presented here) show no evidence of ultrafine grains and twins.

The tensile stress-strain curves of the samples $\mathrm{T}_{\text {SMAT-550 }}$ and $\mathrm{T}_{\text {SMAT-650 }}$ are given in Fig. 7 a) and b) respectively. For comparison, the stress-strain curves of the laminates co-rolled without SMAT ( $\mathrm{T}_{\text {no SMAT-550 }}$ and $\mathrm{T}_{\text {no SMAT-650) }}$ ) and of an as-received coarse-grained sample are also included. It can be observed that the annealing temperature has a significant effect on the mechanical response. With respect to the sample $\mathrm{T}_{\mathrm{SMAT}-550}$, a yield strength reduction of $10 \%$ is recorded in both tensile directions (RD and TD) for the sample $\mathrm{T}_{\text {SMAT-650. }}$. In the rolling direction, sample $\mathrm{T}_{\mathrm{SMAT}-550}$ reaches a yield strength of $750 \mathrm{MPa}$, corresponding to an increase of $154 \%$ as compared to the coarse grain sample (295 MPa). The benefit of the duplex process in terms of mechanical strength appears clearly by comparing the stress-strain curves of the laminates $\mathrm{T}_{\mathrm{SMAT}-550}$ and $\mathrm{T}_{\text {No SMAT-550: }}$ SMAT at the interfaces increases the yield strength by approximately $14 \%$ for both directions. Since the laminates have been manufactured under identical conditions (reduction ratio, annealing temperature and the number of passes), the yield strength increase recorded in figure Fig. 7 can be entirely attributed to the presence of a SMAT induced refined microstructure near the interfaces. At $650^{\circ} \mathrm{C}$, the increase is about $5 \%$.

In accordance with the well known Hall-Petch relationship, the high strength of the co-rolled laminate $\mathrm{T}_{\mathrm{SMAT}-550}$ can be explained by an increased volume fraction of nano- and ultrafine grains. As shown in several publications, nanocrystalline layers can sustain an important part of the load and greatly increase the mechanical strength of the material $[3,5]$. Therefore, raising the volume fraction of nano-grain boundaries in the material leads to a strength increase of the whole structure. In addition, and in agreement with the work of Christian et al. [20] and Chen et al. [21], submicrometric twins play a similar role to grains in dislocation blocking. Thus, in a SMA treated material, the effect of the high density of twins can be associated to the effect of the ultrafine and nano-grains [21-23]. An increase of the volume fraction of nano-grains and submicrometric twins of about $5 \%$ in $\mathrm{T}_{\text {SMAT-550 }}$ thus leads to a significant yield strength enhancement of about $100 \mathrm{MPa}$ with respect to $\mathrm{T}_{\text {SMAT-650. The lower yield }}$ strength of $\mathrm{T}_{\text {SMAT-650 }}$ might be attributed to thermally activated recovery and partial recristallisation of the microstructure initiating dislocation and twin annihilation, as well as grain growth. Fig. 5 supports this hypothesis; it shows that the microstructural changes induced by SMAT are reversed for $\mathrm{T}_{\text {SMAT-650, }}$ contrarily to $\mathrm{T}_{\text {SMAT-650. }}$. Furthermore, increase of the tensile strain up to failure for this sample can be explained by the same phenomena. Of note in Fig. 7 a) is the drop in the stress-strain curve of sample

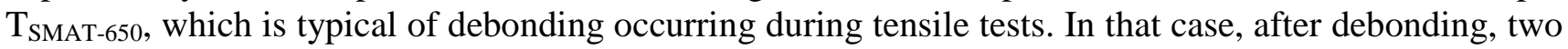
sheets of the multilayer structure have been torn apart and only the third one remains. During mechanical testing, no debonding has been observed for laminates co-rolled at $550^{\circ} \mathrm{C}$, which suggests that the interface of the laminate annealed at $650^{\circ} \mathrm{C}$ is less resistant than that annealed at $550^{\circ} \mathrm{C}$. The integrity of the oxide layer, i.e. the lack of contact areas between the fresh metal (metal-metal contact) of the two adjacent sheets, might explain this phenomenon.

The difference in tensile strain to failure between the samples loaded in their rolling direction (RD) or transverse direction (TD) is not clearly explained yet. Nevertheless, the rearrangement of dislocations leading to the formation of a crystallographic texture during the rolling process might be one possible cause. Furthermore, the heterogeneous material flow and the presence of uncompleted bonding near the interface region may modify the global mechanical response. Electron Backscattering Diffraction (EBSD) measurements and microstructural observations are currently under way to analyse the texture 
evolution during the process. The purpose is to correlate mechanical response (strength and strain to failure) with microstructural changes.

\section{Conclusions}

In the present study, the interface oxidation occurring during a recently developed duplex process combining the Surface Mechanical Attrition Treatment (SMAT) and the co-rolling process at high temperature has been investigated. Optical micrographs of the interface region of the co-rolled laminates have shown discontinuous oxide clusters with heterogeneous thicknesses for sample $\mathrm{T}_{\text {SMAT-550 }}$ and a continuous oxide layer with a uniform thickness of 1-2 $\mu \mathrm{m}$ for sample $\mathrm{T}_{\text {SMAT-650. }}$. The surface nanocristallisation technique used in the duplex process is thought to cause surface pollution, and EDX microanalyses of the oxidised interface region show the presence of elements such as Ti, which points to the TA6V ultrasonic resonator as their main source.

The oxide islets in the laminate processed at $550^{\circ} \mathrm{C}$ significantly disturb the material flow during the co-rolling, leading to strain localisation in bands. Higher annealing temperatures reduce this effect, as no similar bands are observed for sample $\mathrm{T}_{\mathrm{SMAT}-650}$. However, annealing at $650^{\circ} \mathrm{C}$ eliminates SMATinduced mechanical twins. TEM micrographs taken beneath the interface of $\mathrm{T}_{\text {SMAT-550 }}$ show a microstructure characterised by a high density of dislocations, ultrafine equiaxed grains at random crystallographic orientations, and sub-structures. This indicates that grain growth remains limited after co-rolling at $550^{\circ} \mathrm{C}$, contrarily to $650^{\circ} \mathrm{C}$.

Finally, a significant effect of the annealing temperature on the mechanical response is observed in tensile tests: a yield strength reduction of $10 \%$ is recorded for the sample $\mathrm{T}_{\mathrm{SMAT}-650}$ with respect to sample $\mathrm{T}_{550}(\approx 750 \mathrm{MPa})$. This decrease is thought to result from thermally activated recovery and recristallisation of the microstructure, initiating annihilation of dislocations and twins combined with grain growth. Moreover, the higher temperature causes a drop in the interface resistance, leading to interface debonding under stress.

\section{Acknowledgements}

The authors are grateful to D. Bouleau from the Research and Development Laboratory from ArcelorMitall Maizières-lès-Metz (France) for valuable experimental assistance and for helpful discussions.

\section{References}

[1] J. Lu, K. Lu, Comprehensive Structural Integrity, Fracture of Materials from Nano to Macro 8 (2005) 1039-1044.

[2] Y.M. Wang, K. Wang, D. Pan, K. Lu, K.J. Hemker, E. Ma, Scripta Mater. 48 (2003) 1581-1586.

[3] T. Roland, D. Retraint, K. Lu, J. Lu, Scripta Mater. 54 (2006) 1949-1954.

[4] N.R. Tao, Z.B. Wang, W.P. Tong, M.L. Sui, J. Lu, K. Lu, Acta Mater. 50 (2002) 4603-4616.

[5] L. Waltz, D. Retraint, A. Roos, P. Olier, Mater. Sci. Forum Vol. 614 (2009) 249-254.

[6] L. Waltz, D. Retraint, A. Roos, P. Olier, Scripta Mater. 60 (2009) 21-24.

[7] N.R. Tao, M.L. Sui, J. Lu, K. Lu, Acta Met. 11 (1999) 443-440.

[8] X.H. Chen, J. Lu, L. Lu, K. Lu, Scripta Mater. 52 (2005) 1039-1044. 
[9] F. Cemin, F. Echeverrigaray, A.C. Rivani, C.L.G Amorim, R.L.O. Basso, I.J.R. Baumvol, C. A. Figueroa, Mater. Sci. Eng. A 527 (2010) 3206-3209.

[10] X. Wu, N. Tao, Y. Hong, J. Lu, K. Lu, Scripta Mater. 52 (2005) 547-551.

[11] T. Roland, D. Retraint, K. Lu, J. Lu, Mater. Sci. Eng. A 445-446 (2007) 281-288.

[12] H.W. Zhang, Z.K. Hei, G. Liu, J. Lu, K. Lu, Acta Mater. 51 (2003) 1871-1881.

[13] A. Kolahi, A. Akbarzadeh, M.R. Barnett, Journal Mater. Proc. Tech. 209 (2009) 1436-1444.

[14] M.Z. Quadir ; A. Wolz, M. Hoffman, M. Ferry, Scripta Mater. 52 (2005) 1039-1044.

[15] K. Tokumitsu, Mater. Sci. Eng. 101-103 (2007) 23-31.

[16] V.A. Shabashov, A.V. Litvinov, A.G. Mukoseev, V.V. Sagaradze, D.V. Desyatkov, V.P. Pilyugin, I.V. Sagaradze, N.F. Vildanova, Mater. Sci. Eng. A 361 (2003) 136-146.

[17] D. Genève, D. Rouxel, B. Weber, M. Confente, Mater. Sci. Eng. A 435-436 (2006) 1-11.

[18] C.Y. Barlow, P. Nielsen, N. Hansen, Acta Mater. 52 (2004) 3967-3972.

[19] H.R. Le, M.P.F. Sutcliffe, P.Z. Wang, G.T. Burstein, Acta Mater. 52 (2004) 911-920.

[20] J.W. Christian, S. Mahajan, Prog. Mater. Sci. 39 (1995) 1-157.

[21] X.H. Chen, L. Lu, Scripta Mater. 57 (2007) 133-136.

[22] Y.F. Shen, L. Lu, Q.H. Lu, Z.H. Jin, K. Lu, Scripta Mater. 52 (2005) 989-994.

[23] X.H. Chen, L. Lu, K. Lu, Scripta Mater. 64 (2011) 311-314. 


\begin{tabular}{|c|c|c|c|c|c|c|c|c|c|c|c|c|}
\hline Elements & $\mathbf{C}$ & $\mathbf{S i}$ & $\mathbf{M n}$ & $\mathbf{P}$ & $\mathbf{S}$ & $\mathbf{C r}$ & $\mathbf{M o}$ & $\mathbf{N i}$ & $\mathbf{N}$ & $\mathbf{C u}$ & $\mathbf{B}$ & $\mathbf{C o}$ \\
\hline $\boldsymbol{w} \boldsymbol{t} \%$ & 0,025 & 0,38 & 1,33 & 0,027 & 0,002 & 16,70 & 2,09 & 10,20 & 0,030 & 0,40 & 0,0006 & 0,07 \\
\hline
\end{tabular}

Table I - Chemical composition of the 316L austenitic stainless steel (Fe matrix). 


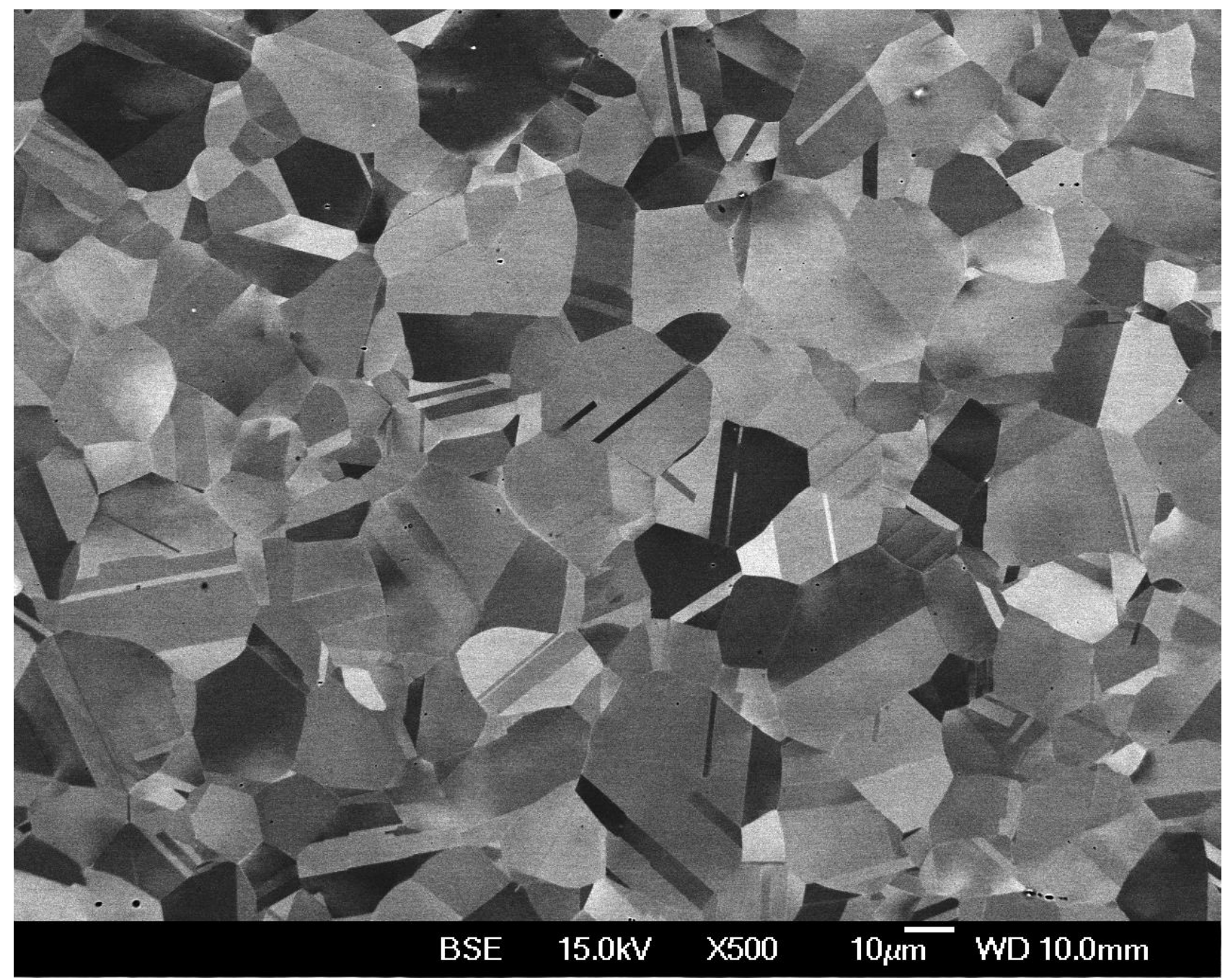

Fig. 1: SEM micrograph showing the microstructure of the as-received 316L stainless steel. 


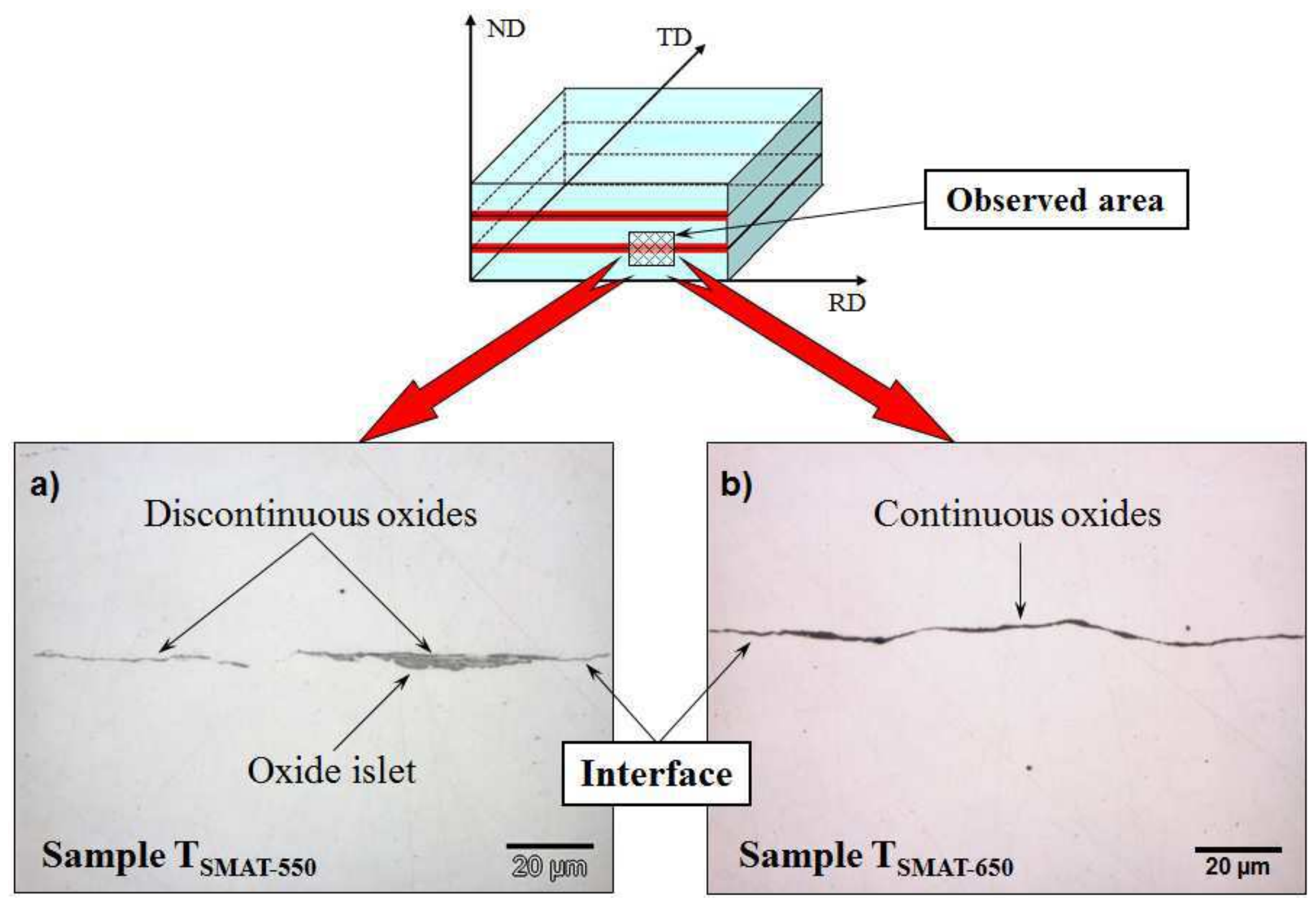

Fig. 2: a-b) Optical micrographs showing the interfaces of samples $\mathrm{T}_{\mathrm{SMAT}-550}$ and $\mathrm{T}_{\mathrm{SMAT}-650}$ in the RD-ND observation plane. 
a)
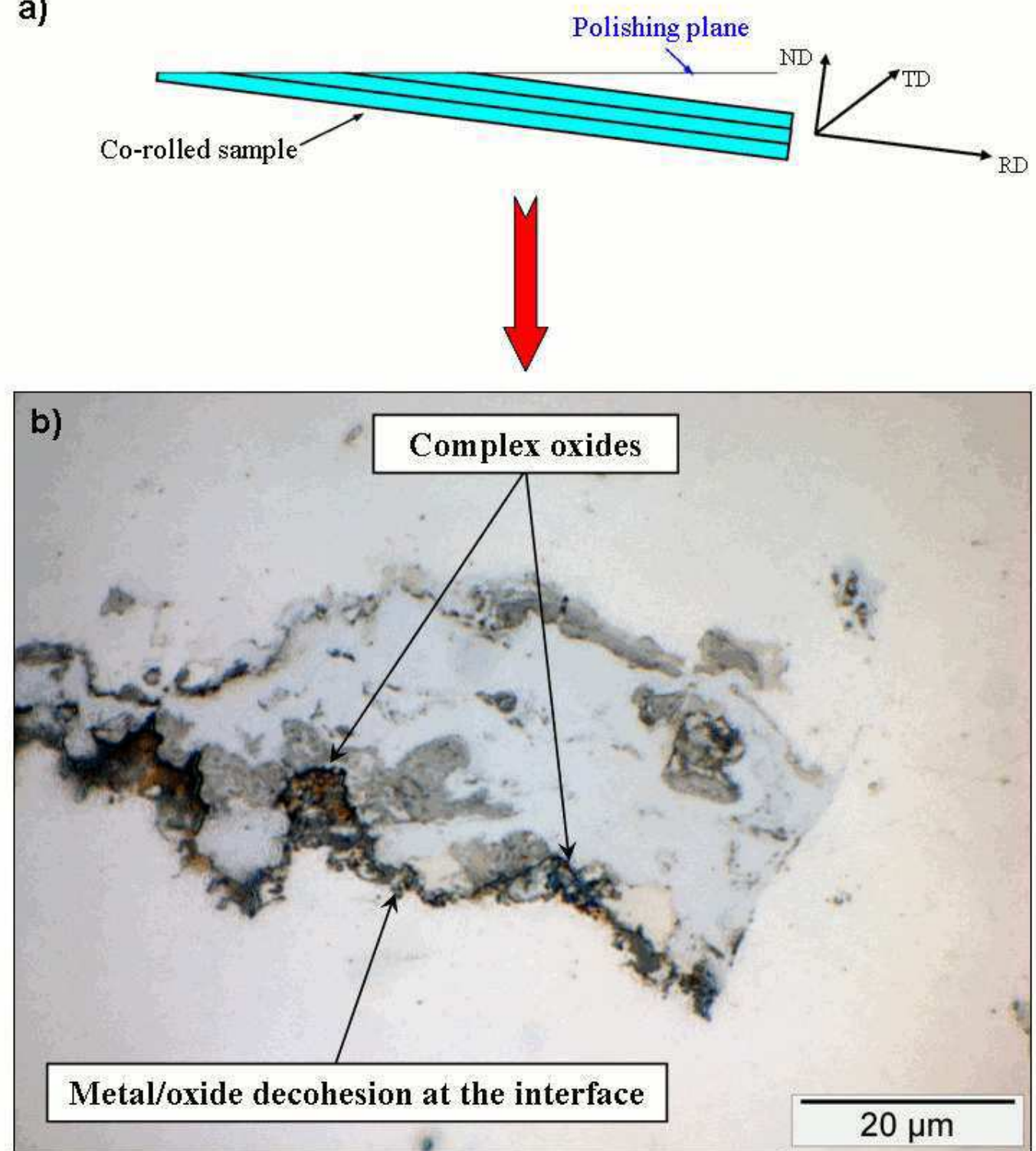

Fig. 3: a) Sample preparation to obtain an inclined polishing plane (near RD-TD); b) Optical micrograph of an oxide islet with metal/oxide decohesion at the interface of sample $\mathrm{T}_{\mathrm{SMAT}-550}$. 


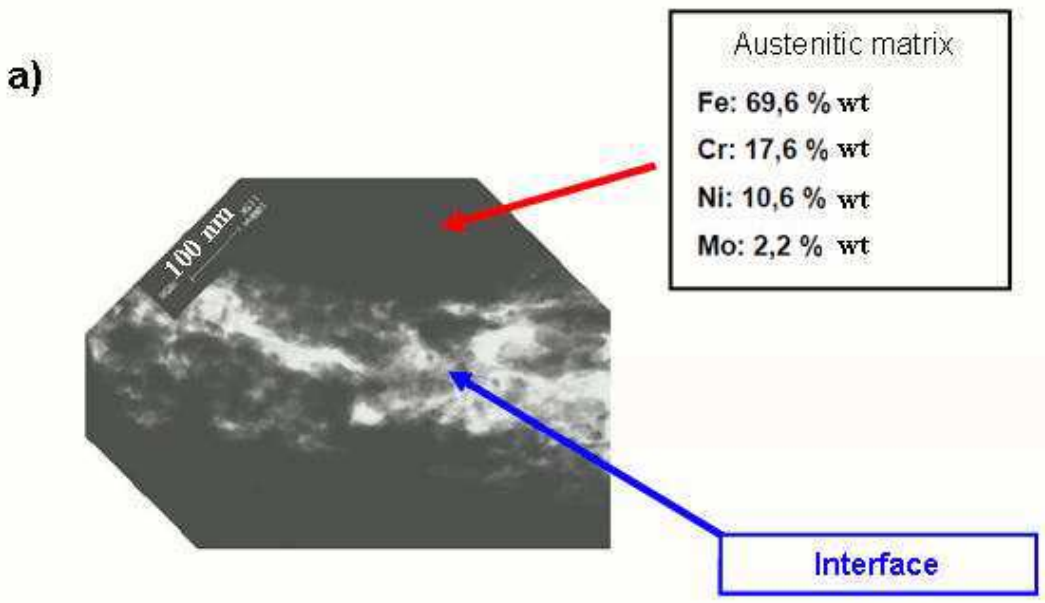

b)

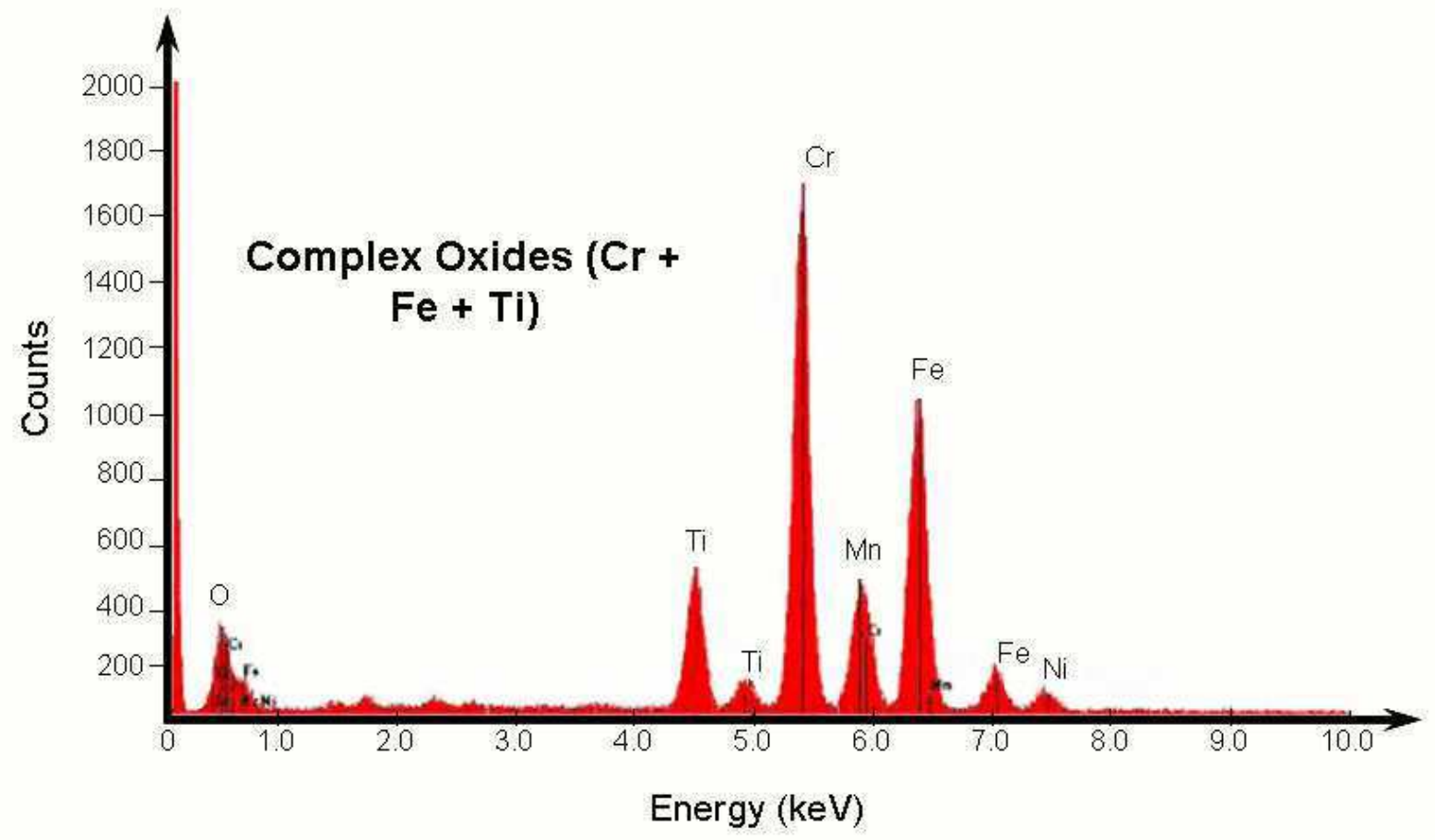

Fig. 4: a) Bright-field TEM observation of the oxide layer at the interface (sample $\mathrm{T}_{\mathrm{SMAT}-550}$ ); $b$ ) EDX analysis of the chemical composition the oxide layer (sample $\mathrm{T}_{\mathrm{SMAT}-550)}$ ). 


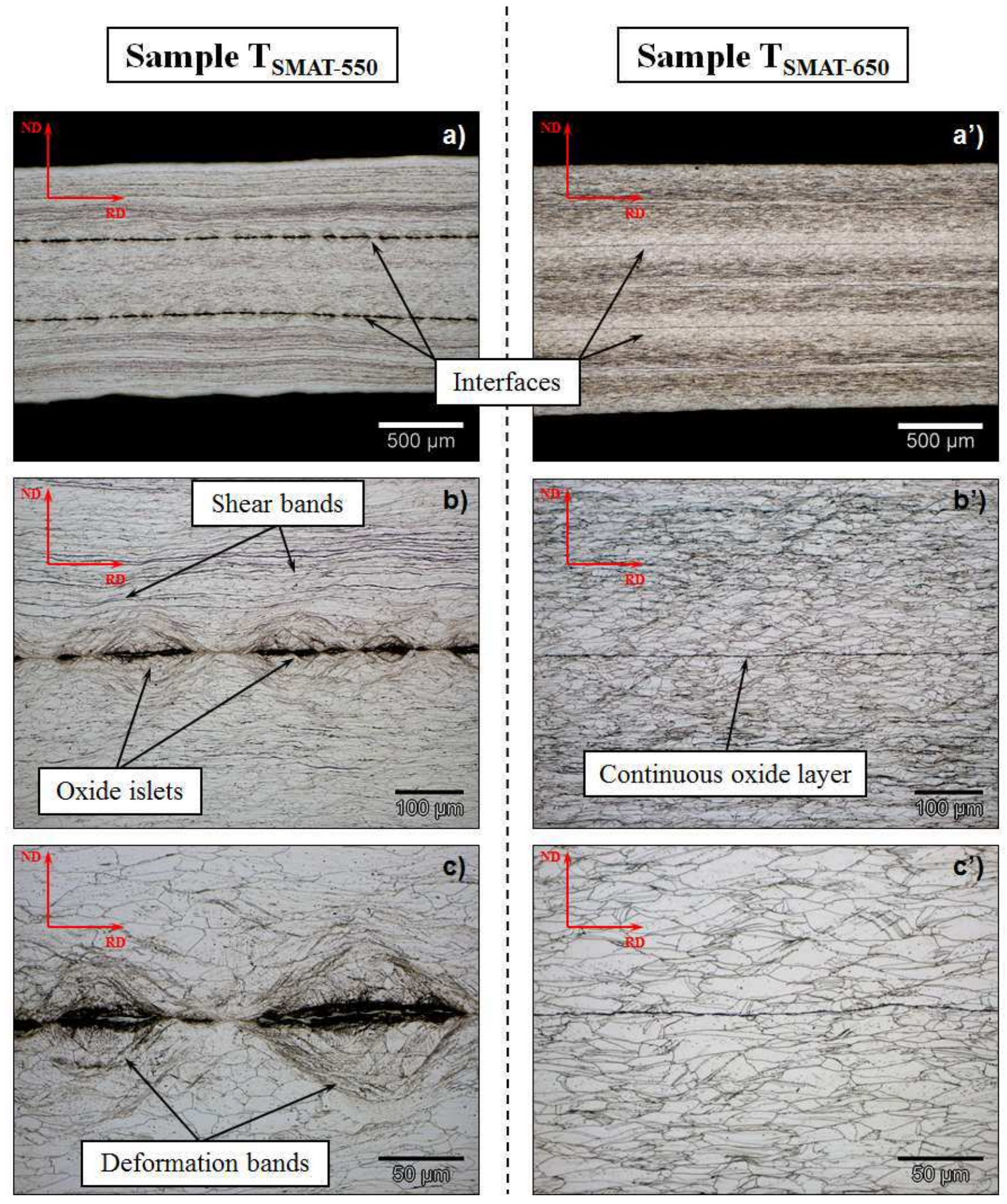

Fig. 5: Optical micrographs of the cross section (plane RD-ND) of samples $\mathrm{T}_{\text {SMAT-550 }}(\mathrm{a}-\mathrm{c})$ and $\mathrm{T}_{\mathrm{SMAT}-650}\left(\mathrm{a}^{\prime}-\mathrm{c}^{\prime}\right)$. 


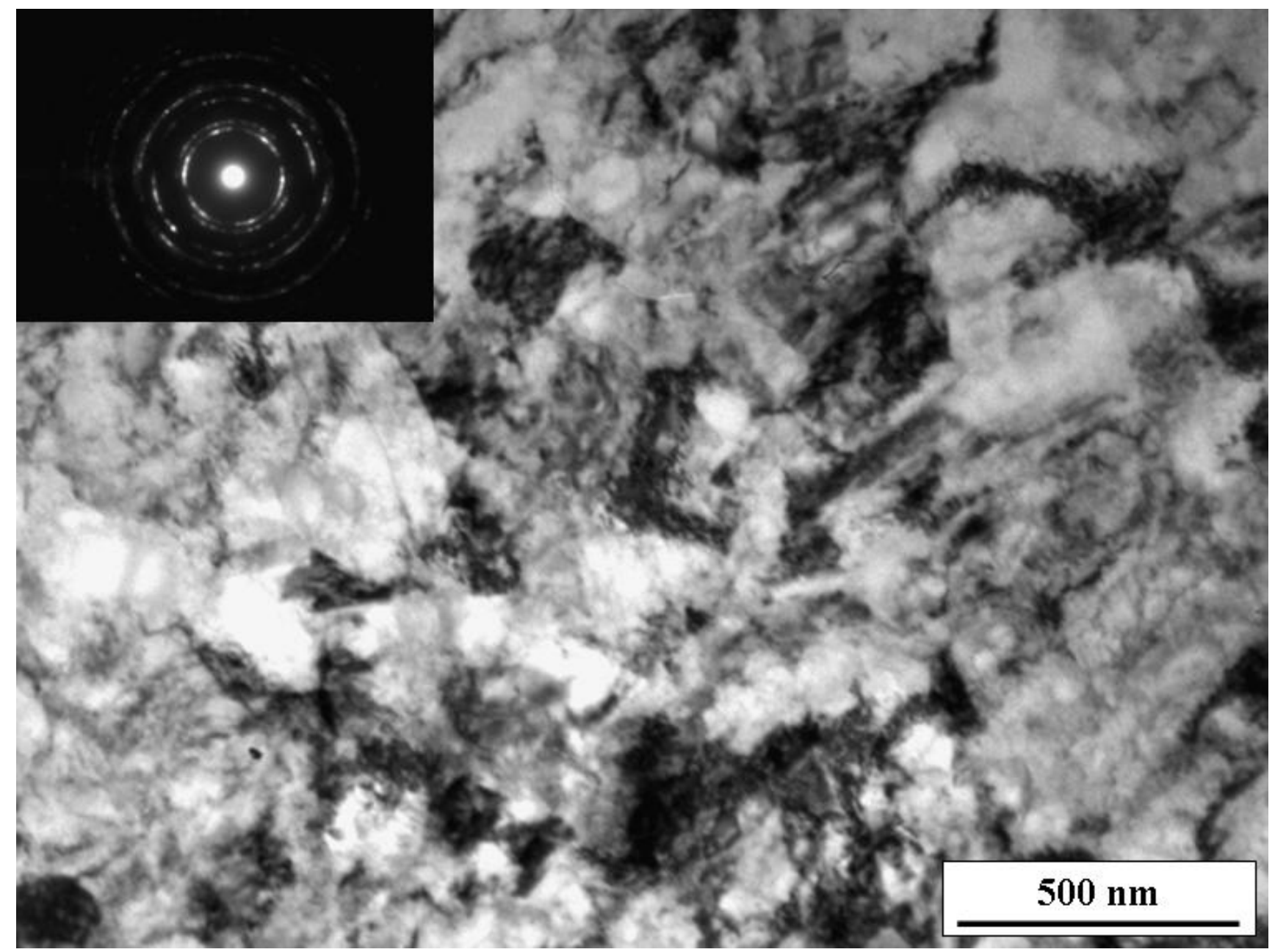

Fig. 6: Bright-field TEM image, and the corresponding SAED pattern (inset) of the sub-nanocrystalline layer near the interface of sample $\mathrm{T}_{\text {SMAT-550 }}$. 
a)

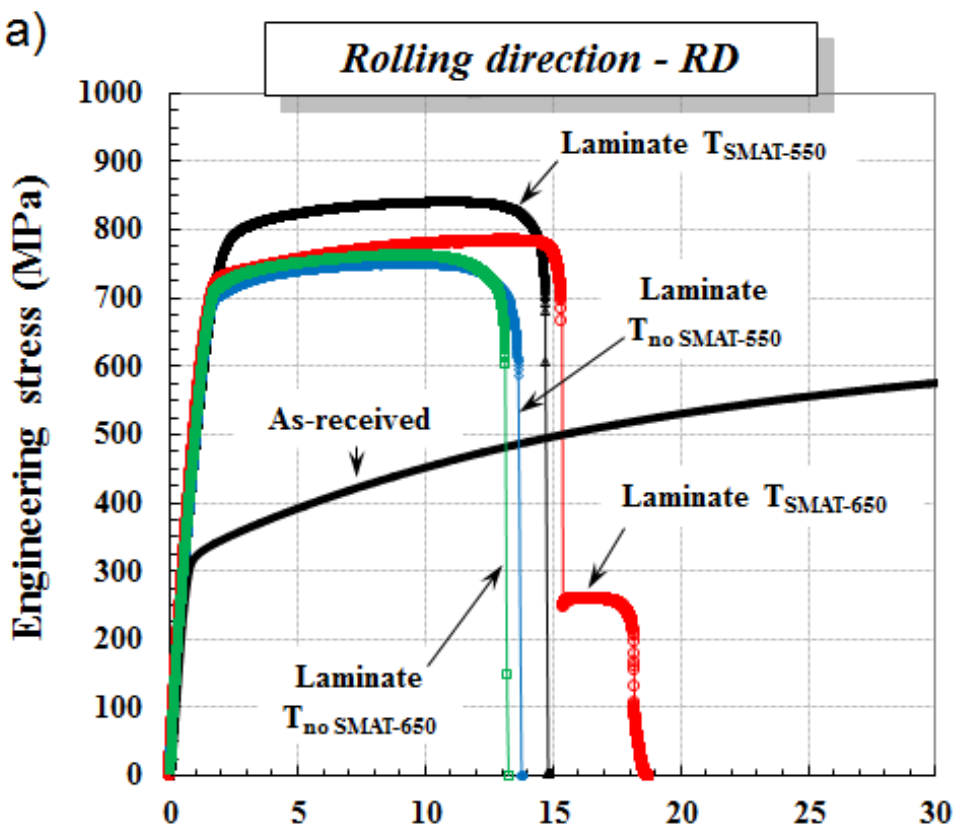

Engineering strain (\%)

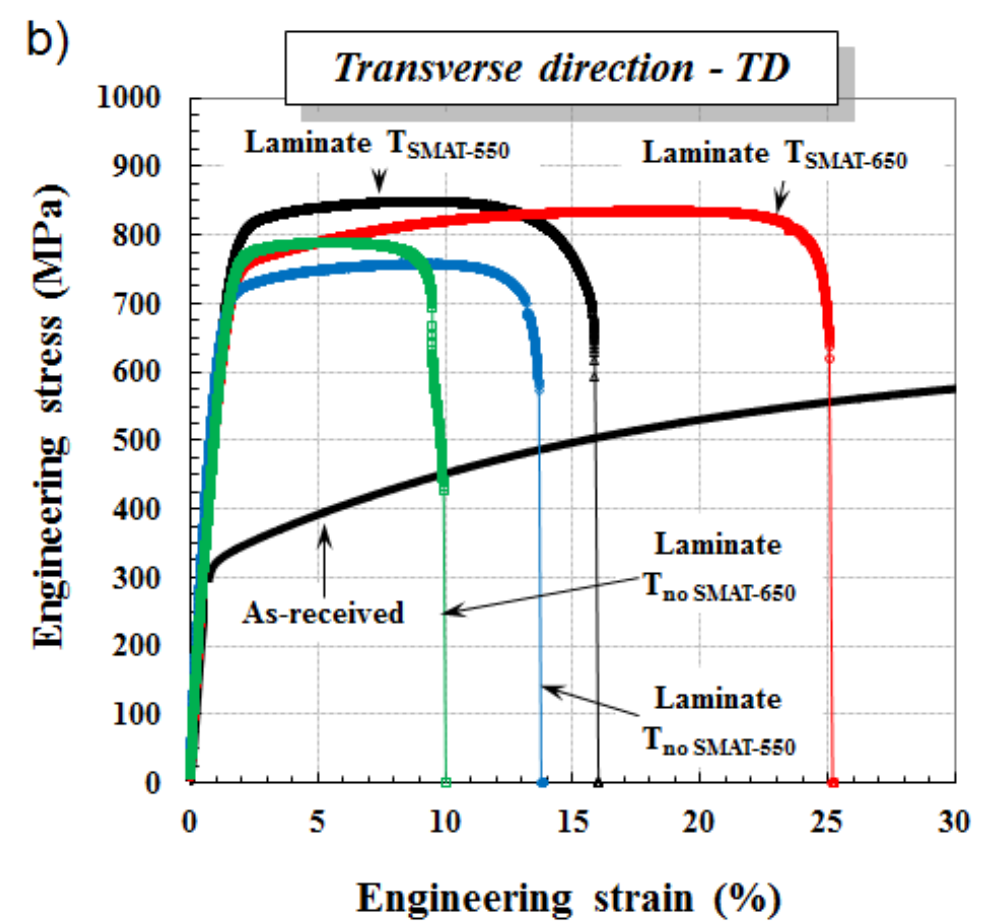

Fig. 7: Uniaxial engineering tensile stress-strain curves of the co-rolled samples $\mathrm{T}_{\mathrm{SMAT}-550}$ and $\mathrm{T}_{\mathrm{SMAT}-650}$ loaded respectively in a) the rolling and $\mathrm{b}$ ) transverse direction. The stress-strain curves of the as-received material and of the samples co-rolled without SMAT at $550^{\circ} \mathrm{C}$ and $650^{\circ} \mathrm{C}\left(\right.$ laminate $\mathrm{T}_{\text {no }} \mathrm{SMAT}-550$ and $\mathrm{T}_{\text {no }} \mathrm{SMAT}$ 650 ) are also given for comparison. 